\title{
The association between ambient temperature and mortality of the coronavirus disease 2019 (COVID-19) in Wuhan, China: a time-series analysis
}

Gaopei Zhu' ${ }^{1}$, Yuhang Zhu ${ }^{1,2} \mathbb{D}$, Zhongli Wang ${ }^{3}$, Weijing Meng ${ }^{4}$, Xiaoxuan Wang ${ }^{1}$, Jianing Feng ${ }^{1}$, Juan Li $^{1}(\mathbb{D}$, Yufei Xiao ${ }^{1}$, Fuyan Shi ${ }^{1 *}$ and Suzhen Wang ${ }^{1 *}$ (D)

\begin{abstract}
Background: The COVID-19 has caused a sizeable global outbreak and has been declared as a public health emergency of international concern. Sufficient evidence shows that temperature has an essential link with respiratory infectious diseases. The objectives of this study were to describe the exposure-response relationship between ambient temperature, including extreme temperatures, and mortality of COVID-19.

Methods: The Poisson distributed lag non-linear model (DLNM) was constructed to evaluate the non-linear delayed effects of ambient temperature on death, by using the daily new death of COVID-19 and ambient temperature data from January 10 to March 31, 2020, in Wuhan, China.

Results: During the period mentioned above, the average daily number of COVID-19 deaths was approximately 45.2. Poisson distributed lag non-linear model showed that there was a non-linear relationship (U-shape) between the effect of ambient temperature and mortality. With confounding factors controlled, the daily cumulative relative death risk decreased by $12.3 \%(95 \% \mathrm{Cl}[3.4,20.4 \%])$ for every $1.0^{\circ} \mathrm{C}$ increase in temperature. Moreover, the delayed effects of the low temperature are acute and short-term, with the most considerable risk occurring in 5-7 days of exposure. The delayed effects of the high temperature appeared quickly, then decrease rapidly, and increased sharply 15 days of exposure, mainly manifested as acute and long-term effects. Sensitivity analysis results demonstrated that the results were robust.
\end{abstract}

Conclusions: The relationship between ambient temperature and COVID-19 mortality was non-linear. There was a negative correlation between the cumulative relative risk of death and temperature. Additionally, exposure to high and low temperatures had divergent impacts on mortality.

Keywords: COVID-19, Ambient temperature, Mortality, Distributed lag non-linear model, Negative correlation

\footnotetext{
*Correspondence: shifuyan@126.com; wangsz@wfmc.edu.cn

'Department of Health Statistics, School of Public Health, Weifang Medical

University, No. 7166 Baotong West Street, Weifang 261053, People's Republic

of China

Full list of author information is available at the end of the article
}

C C The Author(s). 2021 Open Access This article is licensed under a Creative Commons Attribution 4.0 International License, which permits use, sharing, adaptation, distribution and reproduction in any medium or format, as long as you give appropriate credit to the original author(s) and the source, provide a link to the Creative Commons licence, and indicate if changes were made. The images or other third party material in this article are included in the article's Creative Commons licence, unless indicated otherwise in a credit line to the material. If material is not included in the article's Creative Commons licence and your intended use is not permitted by statutory regulation or exceeds the permitted use, you will need to obtain permission directly from the copyright holder. To view a copy of this licence, visit http://creativecommons.org/licenses/by/4.0/. The Creative Commons Public Domain Dedication waiver (http://creativecommons.org/publicdomain/zero/1.0/) applies to the data made available in this article, unless otherwise stated in a credit line to the data. 


\section{Background}

Infectious disease is an old and heavy term. From smallpox, plague, cholera, malaria, etc. in the early days of human civilization, to the Ebola hemorrhagic fever (EHF) and the Acquired Immune Deficiency Syndrome (AIDS) in the 1970s and 1980s, all of them have caused a large number of deaths, disabilities and economic losses $[1,2]$. It can be said that the history of human development is a history of humans fighting infectious diseases [3]. Since the twenty-first century, viral respiratory infections, especially that coronavirus-associated pneumonia, have become a severe public health crisis [4]. The Severe Acute Respiratory Syndrome in $2002[5,6]$ and Middle East Respiratory Syndrome in 2012 are typical of these diseases [7, 8]. More recently, the COVID-19 proved that the occurrence of a new and dangerous infectious disease could monopolize governmental activities, cause fear and hysteria, and get a significant impact on the free life of people throughout the world [9].

COVID-19 has attracted attention due to the report of unexplained pneumonia in Wuhan, China $[10,11]$. It was caused by SRAS-COV-2 infection [12], and subsequently spread to many other parts of the world through global travel. At present, COVID-19 outbreaks have occurred in South Korea, Italy, the United States of America, and other countries, and has been defined as a global pandemic [13]. According to incomplete statistics, as of April 30, approximately 3.2 million cases have been confirmed worldwide, with approximately 224,000 deaths. The number of global confirmed cases and deaths continued to increase. The intermittent emergence and outbreaks of coronaviruses remind us that they pose a severe threat to global health [14].

This epidemic reminds us of the public health crisis that was also caused by coronavirus seventeen years ago. At present, there was clear evidence that the characteristics of this outbreak are similar to those of the 2002 SRAS epidemic [15]. According to the previous research reports, the age, underlying health conditions, and environment were the significant factors determining the spread speed and fatality rate of SARS $[5,16]$. Therefore, we can guess that the above factors may be closely related to COVID-19. It is gratifying that recently some prospective studies [17-19] provide an association between factors (age, basic health situation, and virus transmission speed) and mortality of COVID-19. However, to our best knowledge, some relationship between environmental factors, including meteorological factors and the death risk of COVID-19 patients remain unknown, might need further investigation. Recently, a new study described the relationship between meteorological factors and the death toll of COVID-19. Still, the study hypothesized that there was a non-linear relationship between ambient temperature and the death toll of
COVID-19, and analyzed the relationship between linear lag of temperature and the death toll of COVID-19 [20]. However, this linear delayed effect hypothesis seems to contradict some of the previous general research results. Because a lot of previous studies have confirmed that there was a non-linear delayed effect between temperature and death [21-26]. Furthermore, there was also methodological evidence that it is dangerous and unwise to use the generalized additive model (GAM), with the delayed structure of linear effects, to analyze the relationship while ignoring the non-linear delayed effects. Because this method ignores the non-linear delay effect, thus concealing the real relationship between environmental factors and death [27]. In other words, if the linear correlation assumption is not met, the linear model may be not reliable to estimate the genuine relationship between temperature and death.

In fact, relevant studies have adopted a more appropriate model - distributed lag non-linear model (DLNM) to deal with this situation [28]. Therefore, this model was worth recommended to analyze the non-linear delayed effects between COVID-19 mortality and temperature. Besides, there has been robust evidence that the impact of extreme temperatures needs to be taken into account when focusing on the relationship between average temperature and death, as they may cause unexpected influence on death $[29,30]$. Therefore, analyzing the temperature specific effects between extreme temperatures and COVID-19 mortality was undoubtedly a reasonable choice.

Therefore, a time-series study based on the distributed lag non-linear model was conducted to examine the influence of ambient temperature on mortality outcomes in COVID-19 patients, which can capture the delayed effects of temperature and identify extremely temperaturemortality risks. Additionally, the overall cumulative exposure-response between ambient temperature and COVID-19 death with delayed effects were also analyzed.

\section{Methods \\ Study area}

Figure 1 shows the geographic position of Wuhan city in the east of Hubei Province, which is located where the Yangtze River joins its largest tributary, the Han River. Wuhan covers an area of about $8569.15 \mathrm{~km}^{2}$, and the registered population was 11.212 million in 2019 . Wuhan is located between latitude $29^{\circ} 58^{\prime}-31^{\circ} 22^{\prime} \mathrm{N}$ and longitude $113^{\circ} 41^{\prime}-115^{\circ} 05^{\prime} \mathrm{E}$, which has a subtropical monsoon humid climate with an annual average temperature of $15.8-17.5^{\circ} \mathrm{C}$ and the average yearly rainfall of $1150-1450 \mathrm{~mm}$. The city has four distinct seasons, with cold, wet winter and hot, humid summer. Also, Wuhan is an important science and education base and transportation hub (http://www.wh.gov.cn/zjwh/). 


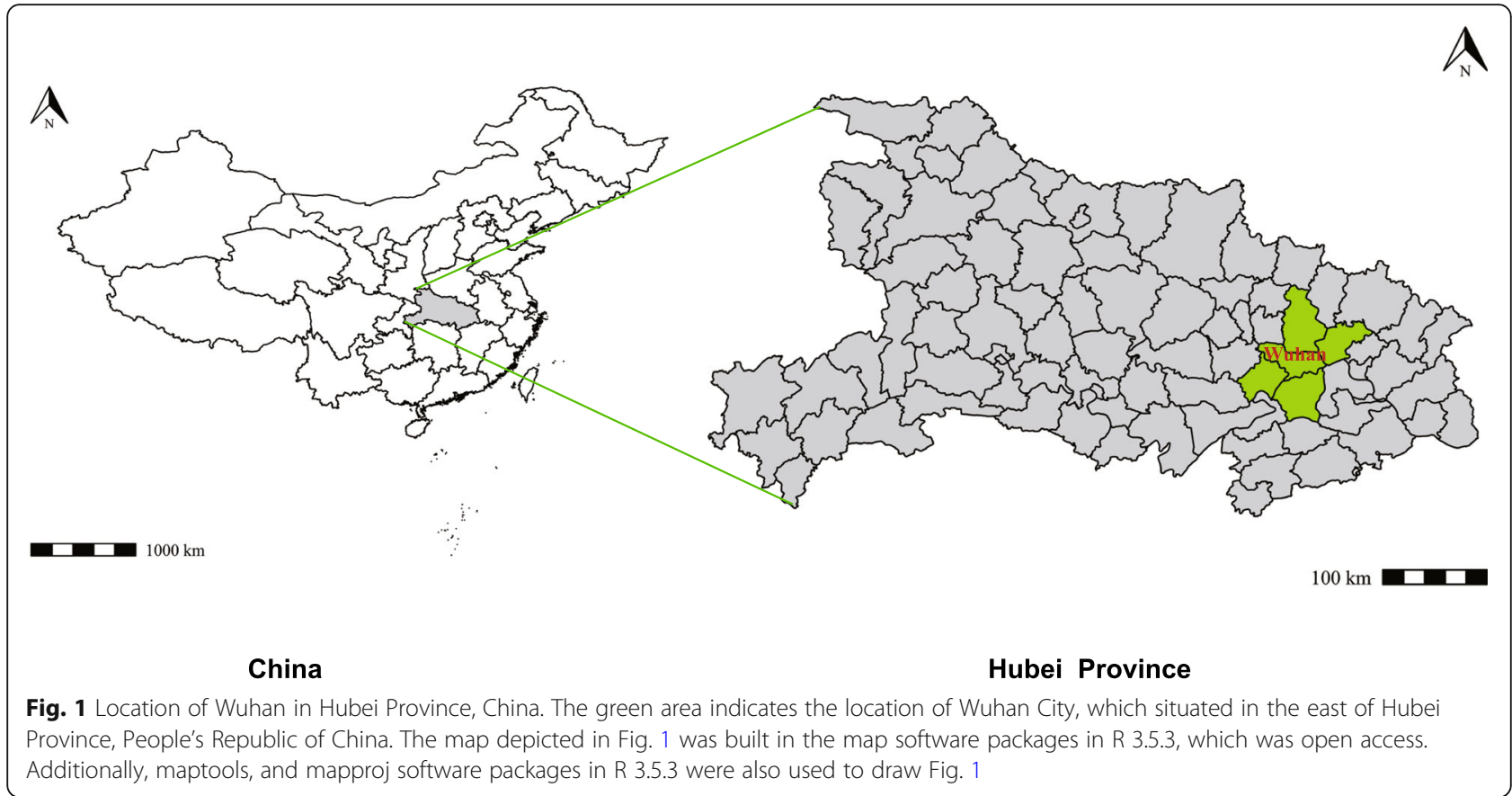

\section{Data collection}

We collected the data on the number of daily new COVID-19 deaths, ambient temperature, humidity, air quality index (AQI), migration scale index (MSI) and urban travel index (UTI) from January 10 to March 31, 2020, in Wuhan.

The urban MSI can show the status of population mobility and reflect the scale of the population migration from a city in a unit time [31]. UTI is an another travelling index, which can be used to measure the population density of inner-city travel. The data of MSI and UTI were obtained from the Baidu map migration platform in the people's Republic of China (https://qianxi.baidu.com/).

The daily COVID-19 death toll was obtained from the websites of the National Health Commission of the People's Republic of China. The daily average temperature and humidity data were obtained from the Meteorological science data sharing service of the People's Republic of China (http://data.cma.cn/site/index.html) and AQI data from air quality monitoring analysis online platform of the People's Republic of China (https://www.aqistudy.cn/ historydata/).

\section{Statistical analysis}

The semi-parametric generalized additive model was used to assess the relationship between environmental epidemiology exposure and death [32-34]. The influence of the latency period of COVID-19 and time of admission were also considered and put into the model. The average incubation period is 5.2 days (range: 2-7 days) $[10,35]$, and the median time of admission was about
10 days [36]. Since the coincidence of the delayed effect of latency period and time of admission in the relationship between temperature and death [37], the temperature delayed period of this study was set to 15 days.

Relative to the total population, daily COVID-19 deaths were defined as a small probability event, which follows the Poisson distribution [38]. The influence of air temperature on health usually has a delayed effect, and the relationship is not linear $[26,39,40]$. In this study, the Poisson function was used as the connection, and the generalized additive model (GAM) was used as the core model. The distributed lag non-linear model (DLNM) was used to analyze the time-series data to estimate the influence of temperature on the death of COVID-19 and the delayed effect. The temperature was included in the form of a cross-basis to estimate its impact on COVID-19 in both variable levels and time lag dimensions. Meanwhile, in order to balance the influence of other factors, relative humidity and AQI were incorporated into the model with the natural cubic spline function, and the model was finally established as follows:

$$
\begin{aligned}
\log \left[\mathrm{E}\left(\mathrm{y}_{\mathrm{t}}\right)\right]= & \alpha+\beta \text { Temperature }_{\mathrm{t}, 1} \\
& +\mathrm{NS}\left(\text { Humidity }_{\mathrm{t}}, \mathrm{df}\right)+\mathrm{NS}\left(\mathrm{AQI}_{\mathrm{t}}, \mathrm{df}\right) \\
& +\mathrm{NS}\left(\text { time }_{\mathrm{dim}} \mathrm{df}\right)+\mathrm{NS}\left(\mathrm{MSI}_{\mathrm{t}}, \mathrm{df}\right) \\
& +\mathrm{NS}\left(\mathrm{UTI}_{\mathrm{t}}, \mathrm{df}\right)
\end{aligned}
$$

$y_{t}$ is the number of death cases of COVID-19 on day $t$, which follows the Poisson distribution of $E\left(y_{t}\right) . \alpha$ is the constant term of the model, Temperature $t_{t, l}$ is the cross 
basis of temperature and delay time, $\beta$ is its coefficient. $N S$ is the natural spline function. Adjust variables such as relative humidity and AQI. Humility H $_{t}$ is day $t$ relative humidity. $\mathrm{AQI}_{t}$ is day $t$ air quality index. $\mathrm{MSI}_{t}$ is day $t$ migration scale index and $\mathrm{UTI}_{t}$ is day $t$ urban travel index. $l$ and $d f$ are the delay days and degrees of freedom, respectively, and time is the date of day $t$.

Sensitivity analyzes were performed to assess the robustness of the model. First, we assessed cumulative exposure using the mean temperatures of successive 0 $14,0-15$, and $0-16$ days, respectively. Secondly, we apply different degrees of freedom (6-8) to time to adjust the unmeasured time-varying confounding. Finally, the robustness of the results was evaluated by removing the daily average AQI or daily average relative humidity, respectively.

The tests were two-sided, and values of $p<0.05$ were considered statistically significant. All statistical analysis and graphic plotting were conducted with the free software environment- $\mathrm{R}$ (version 3.5.3, $\mathrm{R}$ Development Core Team, March 2020). Specifically, we used the software packages 'mgcv' and 'dlnm' to examine the effects of non-linear delayed effects. Besides, the 'dlnm' package was also used to construct a cross-basic matrix for mortality and temperature. All the software packages used above are publicly available on the $\mathrm{R}$ Comprehensive Archive Network (CRAN) (https://cran.r-project.org/).

\section{Results}

\section{Descriptive analysis}

By March 31, 2020, a total of 50,007 cases and 2553 deaths were reported in Wuhan, accounting for $73.75 \%$ of the cumulative COVID-19 deaths in China. The case fatality rate was $5.10 \%$. Table 1 summarized the characteristics of the number of deaths, AQI, and relative humidity of COVID-19 in Wuhan from January 10 to March 31, 2020. The maximum number of deaths on COVID-19 was 216 , and the minimum was 0 . The daily average temperature was $9.0^{\circ} \mathrm{C}$, and the maximum temperature was $20.6^{\circ} \mathrm{C}$. Figure 2 shows the daily distribution of the number of deaths and the mean temperature on COVID-19. The results showed that the temperature was gradually increasing, and the death number of COVID-19 gradually increased and then decreased in Wuhan.

\section{Association of temperature lag and COVID-19 mortality}

Using the Poisson generalized additive model for time series analysis, the correlation between the daily log of COVID-19 mortality and temperature and 15 lag days was visualized (Fig. 3a). From the figure, the correlation is U-shaped, and the delayed effect is non-linear. Besides, compared with the average temperature, when the temperature is lower, COVID-19 mortality is higher. As the ambient temperature increases, the Log (mortality) of COVID-19 patients due to temperature initially decreases rapidly and then slowly increases.

Figure $3 \mathrm{~b}$ displays the overall correlation between cumulative relative risk of COVID-19 death and temperature, which is L-shaped. A significant negative association was shown between the temperature and the daily risk of COVID-19 death, in other words, a $1.0^{\circ} \mathrm{C}$ increase in temperature was associated with a $12.3 \%$ (95\% CI [3.4, 20.4\%]) reduction in daily cumulative relative risk of COVID-19 death. When the temperature was lower than $20.0^{\circ} \mathrm{C}$, the relative risk of death is approaching 0 while it was close to $20.0^{\circ} \mathrm{C}$. Overall, the cumulative relative death risk of COVID-19 decreased with increasing temperature.

Figure 4 shows the general pattern of the relative risk death as a function of temperature and lag, by showing a three-dimensional plots of relative death risk along with temperature and lag 15 days. Overall, the effect of temperature on the daily mortality risk of COVID-19 was non-linear, with higher temperatures leading to lower relative risk. Figure 5 shows the relative mortality for the lag-specific effects $(0,5,10,15$ days $)$ and temperatures-specific effects $\left(-5.0,2.0,10.0,20.0^{\circ} \mathrm{C}\right)$. The death risk of COVID-19 at low temperature presented acute and short-term effects, and it showed a trend of first strong and then weak, with the greatest risk occurring in 5-7 days of exposure. The delayed effects of the high temperature appeared quickly, then decrease rapidly, and increased sharply 15 days of exposure, the

Table 1 Statistics of daily death cases and mean temperature in Wuhan

\begin{tabular}{|c|c|c|c|c|c|c|c|c|}
\hline Variable & $\mathrm{N}_{0}$ (day) & Mean & SD & Min & $P(25)$ & Median & $P(75)$ & Max \\
\hline COVID-19 Mortality Counts & 82 & 32.4 & 38.8 & 0 & 5.0 & 19.0 & 49.7 & 216.0 \\
\hline Temperature $\left({ }^{\circ} \mathrm{C}\right)$ & 82 & 9.0 & 5.1 & 1.2 & 4.8 & 8.4 & 12.3 & 20.6 \\
\hline Relative humility (\%) & 82 & 81.2 & 7.9 & 59.0 & 76.7 & 82.0 & 87.0 & 97.0 \\
\hline $\mathrm{AQI}$ & 82 & 63.6 & 26.9 & 20.0 & 41.5 & 60.0 & 77.2 & 142.0 \\
\hline MSI & 82 & 1.1 & 1.4 & 0.3 & 0.3 & 0.4 & 1.25 & 4.8 \\
\hline UTI & 82 & 1.4 & 1.4 & 0.6 & 5.2 & 0.7 & 0.6 & 1.3 \\
\hline
\end{tabular}

Note: $N_{0}$ the number of days, $S D$ standard deviation, Min the minimum value, Max the maximum value, $A Q I$ air quality index, MSI migration scale index, UTI urban travel index, $P$ (25) upper quartile, $P(75)$ lower quartile 


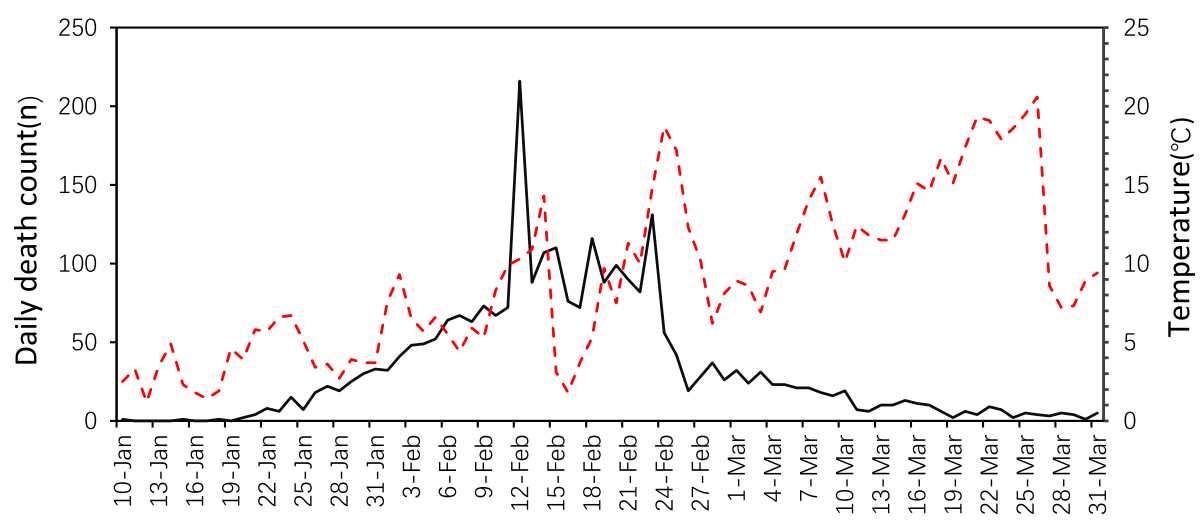

Date

\section{- death - - - temperature}

Fig. 2 The daily distribution of daily death count and mean temperature in Wuhan from 1 January 2020 to 31 March 2020

mortality risk of COVID-19 presented as acute and longer-term effects. Also, low temperatures had a shorter impact on the mortality risk of COVID-19 than high temperatures.

\section{Poisson generalized additive model}

Temperature, humidity, AQI, MSI and UTI were incorporated into the final model. Especially for temperature, the distributed lag nonlinear structure was considered, the then the nonlinear lag period was set as 15 days, along with the degree of freedom of the long-term trend of time that was set as 7. After adjusting for humidity, AQI, MSI, and UTI, the relative risk of COVID-19 death decreased by $5.4 \%(95 \% \mathrm{CI}[3.4,6.9 \%])$ for every $1{ }^{\circ} \mathrm{C}$ rise in average temperature (Table 2). Humidity, AQI, and MSI had no significant effect on COVID-19 deaths. In addition, for per 1-unit increase in UTI, the relative risk of COVID-19 death nearly doubled: 1.959 (95\%CI $[1.009,3.804])$.

\section{Sensitivity analyses}

Changing the time degree of freedom (6-8) could control long-term trends and seasonality. Some influencing factors were eliminated to obtain the adjustment model. In this study, relative humidity and AQI were eliminated, respectively. Table 3 shows that under the conditions of temperature lag0-14 days, lag0-15 days, and lag0-16 days, the average cumulative death effects (RR $[95 \% \mathrm{CI}]$ ) of

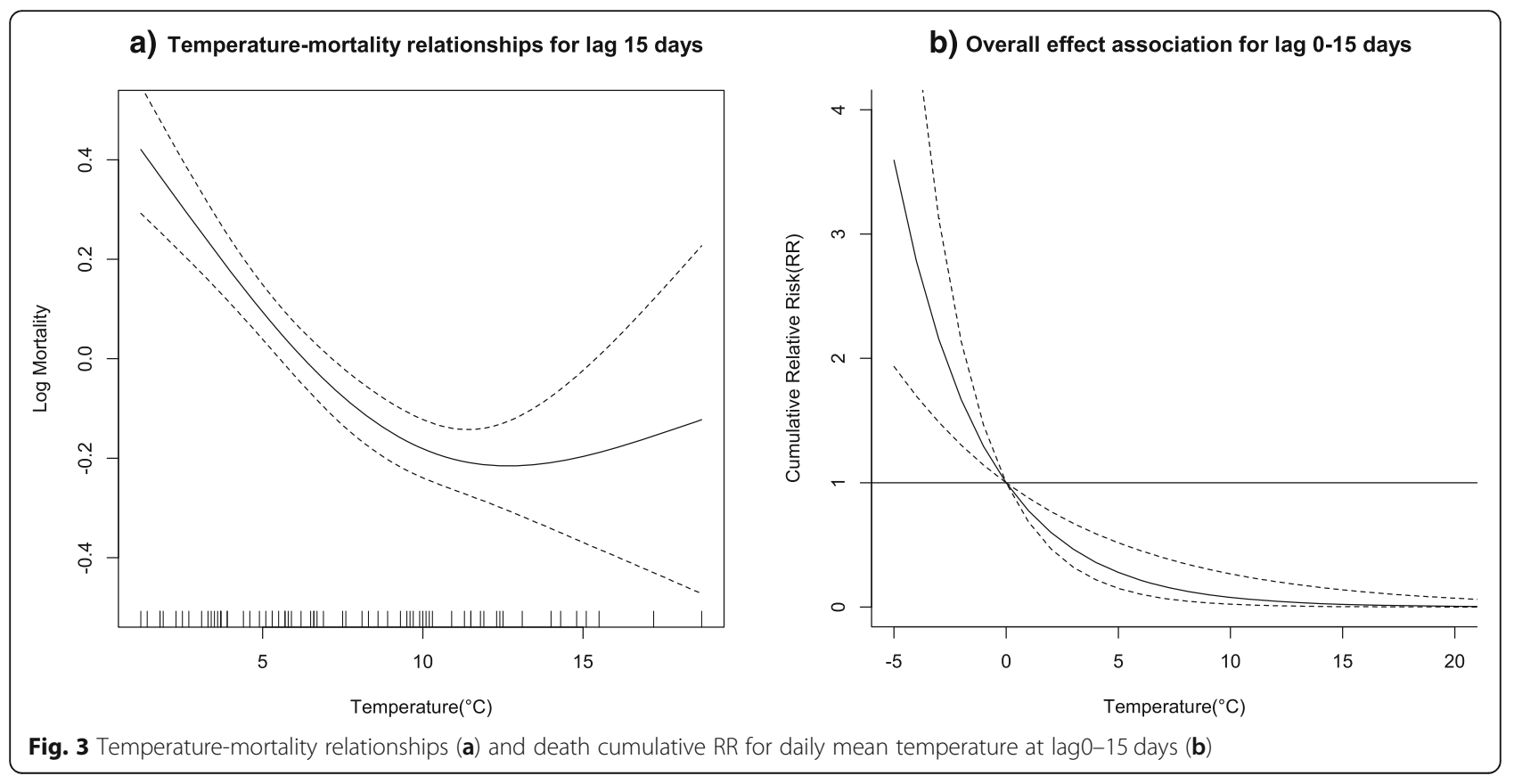


a) 3-Dimensional graph between temperature and death $\mathrm{RR}$

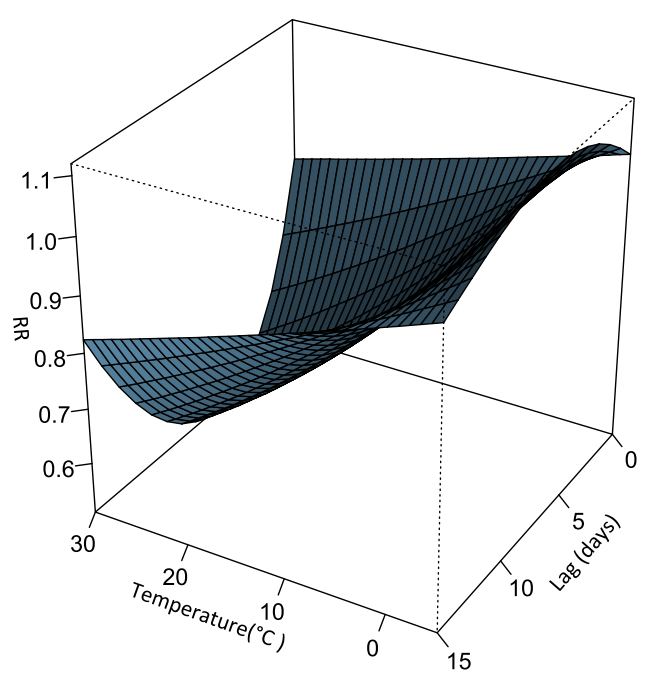

b) Contour plot between temperature and death RR

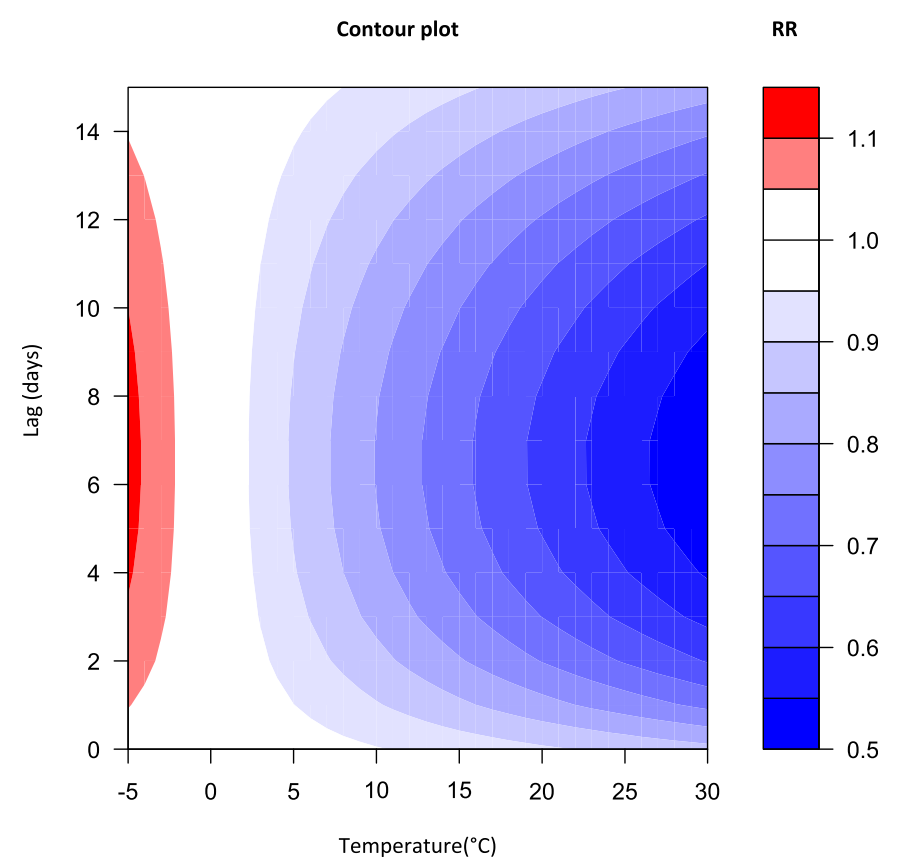

Fig. 4 Relative risks of mortality by daily mean temperature along 15 lag days

COVID-19 did not change significantly. Under the conditions of temperature lag14 days, lag15 days, and lag16 days, the COVID-19 death effects (RR [95\% CI]) also did not change significantly. In conclusion, the model applied in this study were robust.

\section{Discussion}

There is no doubt that the outbreak of COVID-19 has caused enormous economic loss and health burden around the world. Under such circumstances, independent and robust scientific evidence will undoubtedly provide a powerful weapon to deal with this crisis. We believe that it is significant to clarify the relationship between ambient temperature and mortality of the COVID-19, not only in Wuhan but also in other epidemic areas in the world. In this study, we used a rigorous and scientific mathematical model to reveal the unique relationship between temperature and death caused by COVID-19, even if the association between death and temperature in non-communicable diseases has been established [40]. We hope that the research results can provide some methodological guidance for the response to this crisis.

DLNM model was verified to be a useful tool in this study to assess the non-linear relationship between ambient temperature and COVID-19 mortality on a daily basis, including properly evaluating the non-linear associations and cumulative death relative risks related to temperatures for lag days. The model figures out the non-linear and negative correlation between ambient temperature and COVID-19 mortality [26, 40, 41]. The increase in temperature could reduce the death risk of patients, and the relationship between temperature and death effect was U-shaped.

Our study found that the relationship between death risk of COVID-19 and low temperature was different from the high temperature. The low temperature effect on the death risk of COVID-19 is first enhanced and then weakened. With increasing of outdoor temperature, the death risk of COVID-19 is decreasing. The increase in temperature may reduce the lethal intensity of COVID-19, which is related to the increase of virus inactivation caused by high temperature [36, 42]. When the ambient temperature rose to around $10.0^{\circ} \mathrm{C}$ and continued to rise, the temperature and the death risk of COVID-19 gradually decreased and then increased, which is consistent with the findings in noncommunicable diseases [39]. When the temperature is getting higher and higher beyond the inflection, the death risk of combined diseases such as AIDS, diabetes and hypertension may also increase [23], which potentially increases the death risk of patients with COVID-19. Besides, the low temperature effects are acute and shortterm [43], with the most considerable risk occurring in 57 days of exposure. High temperature mainly reflects the acute effect, and the maximum effect occurs on the 


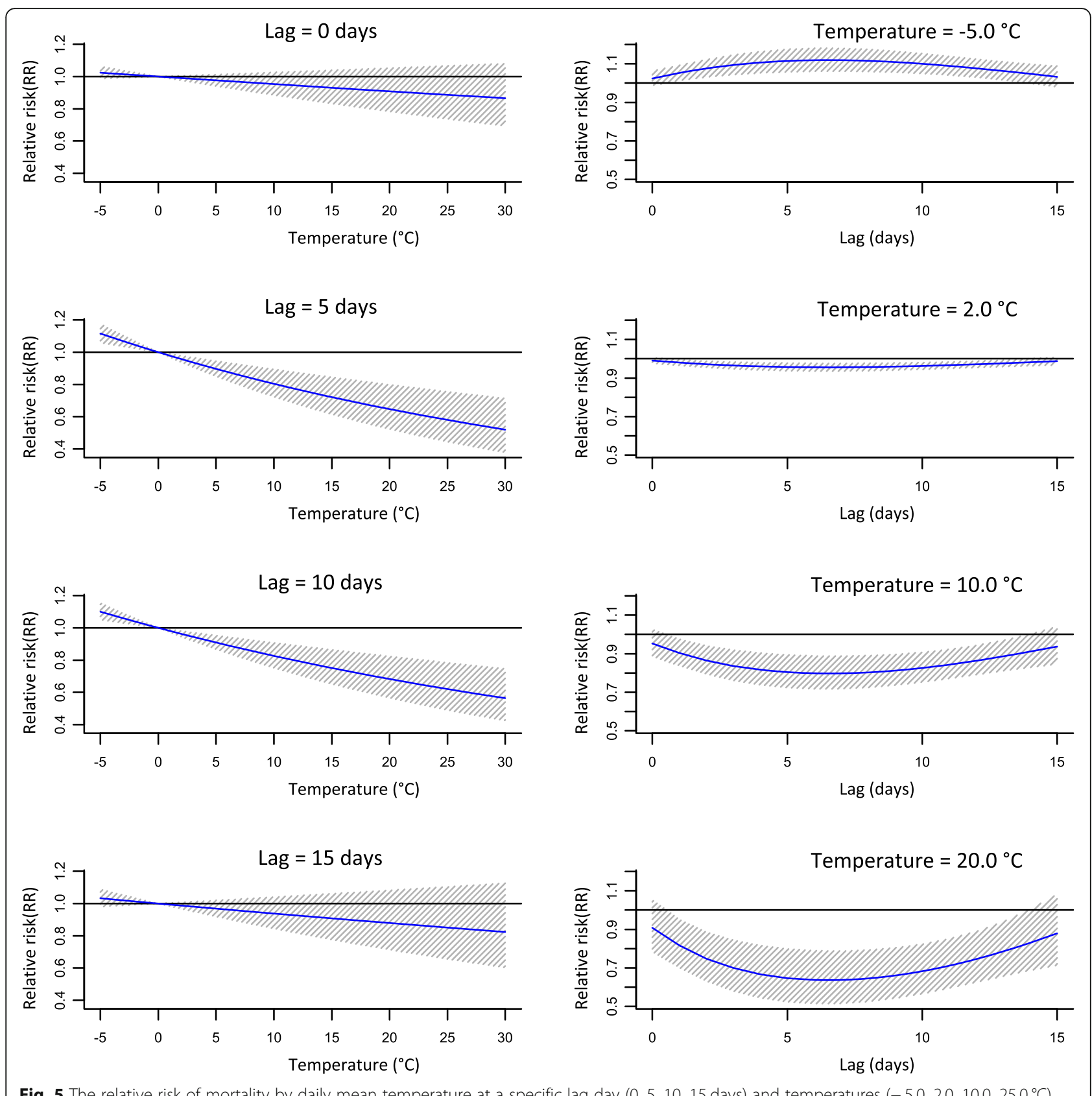

Fig. 5 The relative risk of mortality by daily mean temperature at a specific lag day $(0,5,10,15$ days $)$ and temperatures $\left(-5.0,2.0,10.0,25.0^{\circ} \mathrm{C}\right)$

Table 2 The effect of a one-unit increase in average temperature, relative humility, AQI, MSI and UTI on daily death cases of COVID-19

\begin{tabular}{llll}
\hline Factors & Relative Risk & $\mathbf{9 5 \%} \mathrm{Cl}$ & $\boldsymbol{p}$ value \\
\hline Temperature $\left({ }^{\circ} \mathrm{C}\right)$ & 0.948 & {$[0.931,0.966]$} & $<0.001$ \\
Relative humility $(\%)$ & 0.994 & {$[0.987,1.000]$} & 0.054 \\
AQI & 0.999 & {$[0.996,1.002]$} & 0.534 \\
MSI & 0.642 & {$[0.362,1.137]$} & 0.120 \\
UTI & 1.959 & {$[1.009,3.804]$} & 0.042 \\
\hline
\end{tabular}

Note: $A Q I$ air quality index, MSI migration scale index, UTI urban travel index, $\mathrm{Cl}$ confidence interval

The temperature delayed period of the final model was set to 15 days day of temperature exposure, which is similar to some studies $[44,45]$.

The results of the study show that low temperature has a more significant impact on the death risk of COVID-19 than high temperature is consistent with a meta-analysis [46]. At low temperatures, deaths from respiratory illnesses are greatly affected. Exposure to low temperature in humans can cause cardiovascular stress, which is affected by factors such as peripheral blood vessel constriction, plasma cholesterol, plasma fibrinogen, red blood cell count, blood viscosity, and inflammatory response $[47,48]$. These factors 
Table 3 Sensitivity analysis death RR [95\% CI] of COVID-19 caused by temperature in Wuhan

\begin{tabular}{llllll}
\hline Lag & Model 1 & Model 2 & Model 3 & Model 4 & Model 5 \\
\hline Lag14 & $0.978[0.962,0.996]$ & $0.974[0.956,0.991]$ & $0.972[0.954,0.990]$ & $0.973[0.955,0.990]$ & $0.969[0.952,0.986]$ \\
Lag15 & $0.960[0.943,0.977]$ & $0.956[0.936,0.972]$ & $0.953[0.934,0.971]$ & $0.953[0.935,0.971]$ & $0.946[0.929,0.964]$ \\
Lag16 & $0.977[0.959,0.996]$ & $0.975[0.956,0.994]$ & $0.975[0.956,0.995]$ & $0.973[0.955,0.992]$ & $0.962[0.943,0.980]$ \\
Lag0-14 & $0.945[0.863,1.034]$ & $0.955[0.870,1.049]$ & $0.921[0.832,1.021]$ & $0.965[0.888,1.064]$ & $0.982[0.907,1.063]$ \\
Lag0-15 & $0.878[0.798,0.965]$ & $0.877[0.796,0.966]$ & $0.848[0.765,0.941]$ & $0.891[0.813,0.979]$ & $0.907[0.836,0.983]$ \\
Lag0-16 & $0.823[0.742,0.913]$ & $0.815[0.733,0.906]$ & $0.804[0.723,0.895]$ & $0.830[0.750,0.920]$ & $0.853[0.780,0.932]$ \\
\hline
\end{tabular}

Note: Model 1 long-term degree of freedom is 6, Model 2 long-term degree of freedom is 7, Model 3 long-term degree of freedom is 8 , Model 4 model excluding daily AQI, Model 5 model excluding daily average relative humidity, $R R$ relative risk, Cl confidence interval, Lag the delayed effects situation of temperature, Lag 14 the COVID-19 death effects of the conditions of temperature lag 14 days, Lag0-14 the COVID-19 average cumulative death effects of the conditions of temperature lag 14 days

together lead to respiratory distress, thus contribute to the deterioration of COVID-19 patients. At high temperatures, the number of patients dying from chronic non-communicable diseases increased, which forms a potential competitive relationship, leading to a gentle change in the number of COVID-19 deaths directly attributable to temperature [40, 49].

Overall, the temperature was negatively correlated with the cumulative effect of COVID-19 deaths [24]. At low temperatures, the cumulative death risk of COVID19 was higher. With the increase of daily average temperature, the delayed effects of temperature exposure in patients with COVID-19 decrease rapidly and show protective effects. This data indicates that the risk of death of COVID-19 patients gradually decreases due to the increase in ambient temperature. With the advent of summer, the COVID-19 patient population may benefit from the high temperature effect.

Sensitivity analysis showed that the results of this study were robust. Firstly, the distributed lag non-linear method can flexibly dig out the possible relationship between temperature changes and daily mortality and cumulative delayed effects. Although the model is involved with many parameters, our sensitivity analysis shows that the results are robust [49]. Secondly, during the analysis, we adjusted a group of potential confounding factors, including daily average temperature, relative humidity and AQI, and compared the model results after excluding relative humidity or AQI. Generally, our results were relatively robust.

Some limitations should be considered in interpreting our findings: Firstly, this is an ecologically designed study, and the use of environmental monitoring data may not accurately reflect actual personal exposure. Secondly, COVID-19 patients basically receive isolation treatment in the designated hospital, and the patients live in the closed space, so the relationship between the ambient temperature and death may be different from that of indoor temperature. Third, this study did not adjust the social and demographic factors such as age and economy, which may affect the population structure and mortality [9]. Fourth, individual basic disease information such as diabetes, hypertension and AIDS are not available on the websites of the National Health Commission of the People's Republic of China, which will cause bias to our research results. Finally, in the process of treating and curing COVID-19 patients, clinical diagnosis and treatment guideline is continuously updated, and the impact from this inconstancy was not included in this study.

\section{Conclusion}

Despite these limitations, this study found out the nonlinear Negative correlation between ambient temperature and death in COVID-19 patients. Besides, it was made clear that low temperature can potentially increase the risk of death, while high temperature manifests reversely. However, high temperatures may increase the risk of death from other complications, which are worthy of further study. Altogether, this study may provide a beneficial reference for the setting of COVID-19 clinical isolation and treatment environment.

\section{Abbreviations}

COVID-19: Coronavirus disease 2019; DLNM: Distributed lag non-linear model;; EHF: Ebola hemorrhagic fever; AIDS: Acquired Immune Deficiency Syndrome; AQI: Air quality index; SD: Standard deviation; Min: The minimum value; Max: The maximum value; P (25): Upper quartile; P (75): Lower quartile; RR: Relative risk; Cl: Confidence interval

\section{Acknowledgments}

We are grateful for the data provided by the National Health Commission of the People's Republic of China, China's Air Quality Monitoring Analysis Online Platform, and China Meteorological Data Sharing Service System.

\section{Authors' contributions}

G. Z., contributed to conceptualization, methodology, data curation, software, and original manuscript writing; $Y$. Z., contributed to data curation, methodology, review and editing of writing; Z. W., contributed to the review and editing of writing; W. M., contributed to data curation and the review and editing of writing; X. W., contributed to supervision, software, and validation; J. L., J. F. and Y. X., contributed to supervision and formal analysis; S. W. and F. S., contributed to methodology and the review and editing of writing. All authors gave final approval and agreed to be accountable for all aspects of the work. 


\section{Authors' information}

S. W. is a professor at the department of Health Statistics, School of Public Health, Weifang Medical University, People's Republic of China. She specialized in causal inference of real-world study, health risk assessment research, infectious disease prediction and early warning.

\section{Funding}

This study was partially supported by the National Natural Science Foundation of China (Project approval No.: 81872719, 81803337), the National Bureau of Statistics Foundation Project (Project approval No.: 2018LY79), the Natural Science Foundation of Shandong Province (Project approval No.: ZR2019MH034). The funders did not play any role in the study design, data collection and interpretation of data, or in writing the manuscript.

\section{Availability of data and materials}

The datasets analyzed in this study were publically available. The daily COVID-19 death toll was got from the websites of the National Health Commission of the People's Republic of China (http://www.nhc.gov.cn/). The daily average temperature and humidity data were obtained from Meteorological science data sharing service of China (http://data.cma.cn/site/index.html) and AQI data from air quality monitoring analysis online platform of China (https://www. agistudy.cn/historydata/). The data of MSI and UTI were obtained from the Baidu map migration platform in the people's Republic of China (https://qianxi.baidu $\mathrm{com} /$ ).

\section{Ethics approval and consent to participate}

This was an observational study using national registry data from public platforms. The medical ethics were exempted during the epidemic.

\section{Consent for publication}

Not applicable.

\section{Competing interests}

The author declares that he has no competing interests.

\section{Author details}

'Department of Health Statistics, School of Public Health, Weifang Medical University, No. 7166 Baotong West Street, Weifang 261053, People's Republic of China. ${ }^{2}$ Department of Child and Adolescent Psychiatry, Psychotherapy, and Psychosomatics, Center for Psychosocial Medicine, University Medical Center Hamburg-Eppendorf, Martinistraße 52, W 29, 20246 Hamburg, Germany. ${ }^{3}$ School of Public Health, Cheeloo College of Medicine, Shandong University, Jinan 250012, People's Republic of China. ${ }^{4}$ School of Life Sciences and Technology, Weifang Medical University, No. 7166 Baotong West Street, Weifang 261053, People's Republic of China.

\section{Received: 8 July 2020 Accepted: 25 December 2020}

\section{Published online: 11 January 2021}

\section{References}

1. Jones KE, Patel NG, Levy MA, Storeygard A, Balk D, Gittleman JL, et al. Global trends in emerging infectious diseases. Nature. 2008;451(7181):990-3. https://doi.org/10.1038/nature06536.

2. Malvy D, McElroy AK, de Clerck H, Günther S, van Griensven J. Ebola virus disease. Lancet. 2019;393(10174):936-48. https://doi.org/10.1016/S01406736(18)33132-5.

3. Brachman PS. Infectious diseases - past, present, and future. Int J Epidemiol. 2003:32(5):684-6. https://doi.org/10.1093/ije/dyg282.

4. Farrar J. Science, innovation and society: what we need to prepare for the health challenges of the twenty-first century? Int Health. 2019;11(5):317-20. https://doi.org/10.1093/inthealth/ihz047.

5. WHO. Update 49-SARS case fatality ratio, incubation period. 2003. https:// www.who.int/csr/sarsarchive/2003_05_07a/en/. Accessed 5 April 2020.

6. Sajadi MM, Habibzadeh P, Vintzileos A, Shokouhi S, Miralles-Wilhelm F, Amoroso A. Temperature, humidity, and latitude analysis to predict potential spread and seasonality for COVID-19. SSRN Electron J. 2020. https://doi.org/10.2139/ssin.3550308.

7. AlRuthia Y, Somily AM, Alkhamali AS, Bahari OH, AlJuhani RJ, Alsenaidy M, et al. Estimation Of Direct Medical Costs Of Middle East Respiratory Syndrome Coronavirus Infection: A Single-Center Retrospective Chart
Review Study. Infect Drug Resist. 2019;12:3463-73. https://doi.org/10.2147/ idr.S231087.

8. Emerson JA, Dunsiger S, Williams DM. Reciprocal within-day associations between incidental affect and exercise: An EMA study. Psychol Health. 2018; 33(1):130-43. https://doi.org/10.1080/08870446.2017.1341515.

9. Kraemer MUG, Yang CH, Gutierrez B, Wu CH, Klein B, Pigott DM, et al. The effect of human mobility and control measures on the COVID-19 epidemic in China. Science. 2020;368(6490):493-7. https://doi.org/10. 1126/science.abb4218.

10. Guan WJ, Ni ZY, Hu Y, Liang WH, Ou CQ, He JX, et al. Clinical Characteristics of Coronavirus Disease 2019 in China. NEJM. 2020;382(18):1708-20. https://doi.org/10.1056/NEJMoa2002032.

11. Zhu N, Zhang D, Wang W, Li X, Yang B, Song J, et al. A Novel Coronavirus from Patients with Pneumonia in China, 2019. NEJM. 2020;382(8):727-33. https://doi.org/10.1056/NEJMoa2001017.

12. Huang C, Wang Y, Li X, Ren L, Zhao J, Hu Y, et al. Clinical features of patients infected with 2019 novel coronavirus in Wuhan, China. Lancet. 2020;395(10223):497-506. https://doi.org/10.1016/S01406736(20)30183-5.

13. WHO. WHO Director-General's opening remarks at the media briefing on COVID-19. 2020. https://www.who.int/dg/speeches/detail/who-directorgeneral-s-opening-remarks-at-the-media-briefing-on-covid-19---11-march2020. Accessed 5 April 2020.

14. Chen Y, Liu Q, Guo D. Emerging coronaviruses: Genome structure, replication, and pathogenesis. J Med Virol. 2020;92(4):418-23. https://doi. org/10.1002/jmv.25681.

15. Jiang F, Deng L, Zhang L, Cai Y, Cheung CW, Xia Z. Review of the Clinical Characteristics of Coronavirus Disease 2019 (COVID-19). J Gen Intern Med. 2020;35(5):1545-9. https://doi.org/10.1007/s11606-020-05762-w.

16. Cui Y, Zhang ZF, Froines J, Zhao J, Wang H, Yu SZ, et al. Air pollution and case fatality of SARS in the People's Republic of China: an ecologic study. Environ Health. 2003;2(1):1-5. https://doi.org/10.1186/1476-069X-2-15.

17. Butler MJ, Barrientos RM. The impact of nutrition on COVID-19 susceptibility and long-term consequences. Brain Behav Immun. 2020. https://doi.org/10. 1016/j.bbi.2020.04.040.

18. Du RH, Liang LR, Yang CQ, Wang W, Cao TZ, Li M, et al. Predictors of Mortality for Patients with COVID-19 Pneumonia Caused by SARS-CoV-2: A Prospective Cohort Study. Eur Respir J. 2020:55(5). https://doi.org/10.1183/ 13993003.00524-2020.

19. Grasselli G, Zangrillo A, Zanella A, Antonelli M, Cabrini L, Castelli A, et al. Baseline Characteristics and Outcomes of 1591 Patients Infected With SARSCoV-2 Admitted to ICUs of the Lombardy Region, Italy. JAMA. 2020;323(16): 1574-81. https://doi.org/10.1001/jama.2020.5394.

20. Ma Y, Zhao Y, Liu J, He X, Wang B, Fu S, et al. Effects of temperature variation and humidity on the death of COVID-19 in Wuhan, China. Sci Total Environ. 2020;724. https://doi.org/10.1016/.scitotenv.2020.138226.

21. Ballester F, Corella D, Pérez-Hoyos S, Sáez M, Hervás A. Mortality as a Function of Temperature. A Study in Valencia, Spain, 1991-1993. Int J Epidemiol. 1997;26(3):551-61. https://doi.org/10.1093/ije/26.3.551.

22. Qiao Z, Guo Y, Yu W, Tong S. Assessment of Short- and Long-Term Mortality Displacement in Heat-Related Deaths in Brisbane, Australia, 1996-2004. Environ Health Perspect. 2015;123(8):766-72. https://doi.org/10.1289/ehp. 1307606.

23. Bunker A, Wildenhain J, Vandenbergh A, Henschke N, Rocklöv J, Hajat S, et al. Effects of Air Temperature on Climate-Sensitive Mortality and Morbidity Outcomes in the Elderly; a Systematic Review and Meta-analysis of Epidemiological Evidence. EBioMedicine. 2016;6:258-68. https://doi.org/ 10.1016/j.ebiom.2016.02.034.

24. Dadbakhsh M, Khanjani N, Bahrampour A, Haghighi PS. Death from respiratory diseases and temperature in Shiraz, Iran (2006-2011). Int J Biometeorol. 2017;61(2):239-46. https://doi.org/10.1007/s00484-016-1206-z

25. Lytras T, Pantavou K, Mouratidou E, Tsiodras S. Mortality attributable to seasonal influenza in Greece, 2013 to 2017: variation by type/subtype and age, and a possible harvesting effect. Euro Surveill. 2019;24(14). https://doi.org/10.2807/1560-7917.ES.2019.24.14.1800118.

26. Chen R, Yin P, Wang L, Liu C, Niu Y, Wang W, et al. Association between ambient temperature and mortality risk and burden: time series study in 272 main Chinese cities. BMJ. 2018;363:k4306. https://doi.org/10.1136/bmj.k4306

27. Gasparrini A, Armstrong B, Kenward MG. Distributed lag non-linear models. Stat Med. 2010;29(21):2224-34. https://doi.org/10.1002/sim.3940. 
28. Armstrong B. Models for the Relationship Between Ambient Temperature and Daily Mortality. Epidemiology. 2006;17(6):624-31. https://doi.org/10. 1097/01.ede.0000239732.50999.8f.

29. Ding Z, Li L, Wei R, Dong W, Guo P, Yang S, et al. Association of cold temperature and mortality and effect modification in the subtropical plateau monsoon climate of Yuxi, China. Environ Res. 2016;150:431-7. https://doi.org/10.1016/j.envres.2016.06.029.

30. Ban J, Xu D, He MZ, Sun Q, Chen C, Wang W, et al. The effect of high temperature on cause-specific mortality: A multi-county analysis in China. Environ Int. 2017;106:19-26. https://doi.org/10.1016/j.envint.2017.05.019.

31. Baidu migration. Baidu map insight. http://qianxi.baidu.com/. Accessed 5 April 2020.

32. Borge R, Requia WJ, Yagüe C, Jhun I, Koutrakis P. Impact of weather changes on air quality and related mortality in Spain over a 25year period [1993-2017]. Environ Int. 2019;133(Pt B):105272. https://doi.org/10.1016/j. envint.2019.105272.

33. Liu C, Chen R, Sera F, Vicedo-Cabrera AM, Guo Y, Tong S, et al. Ambient Particulate Air Pollution and Daily Mortality in 652 Cities. NEJM. 2019;381(8): 705-15. https://doi.org/10.1056/NEJMoa1817364.

34. Wu R, Song $X$, Chen D, Zhong L, Huang X, Bai $Y$, et al. Health benefit of air quality improvement in Guangzhou, China: Results from a long time-series analysis (2006-2016). Environ Int. 2019;126:552-9. https://doi.org/10.1016/j. envint.2019.02.064

35. Lauer SA, Grantz KH, Bi Q, Jones FK, Zheng Q, Meredith HR, et al. The Incubation Period of Coronavirus Disease 2019 (COVID-19) From Publicly Reported Confirmed Cases: Estimation and Application. Ann Intern Med. 2020. https://doi.org/10.7326/M20-0504.

36. Chan KH, Malik Peiris JS, Lam SY, Poon LLM, Yuen KY, Seto WH. The Effects of Temperature and Relative Humidity on the Viability of the SARS Coronavirus. Adv Virol. 2011:1-7. https://doi.org/10.1155/2011/734690.

37. Tan J, Mu L, Huang J, Yu S, Chen B, Yin J. An initial investigation of the association between the SARS outbreak and weather: with the view of the environmental temperature and its variation. J Epidemiol Community Health. 2005;59(3):186-92. https://doi.org/10.1136/jech.2004.020180.

38. Warner P. Poisson regression. J Fam Plann Reprod Health Care. 2015;41(3): 223-4. https://doi.org/10.1136/jfprhc-2015-101262.

39. Yang J, Ou CQ, Ding Y, Zhou YX, Chen PY. Daily temperature and mortality: a study of distributed lag non-linear effect and effect modification in Guangzhou. Environ Health. 2012;11(63):1-9. https://doi.org/10.1186/1476069X-11-63.

40. Ma W, Wang L, Lin H, Liu T, Zhang Y, Rutherford S, et al. The temperaturemortality relationship in China: An analysis from 66 Chinese communities. Environ Res. 2015;137:72-7. https://doi.org/10.1016/j.envres.2014.11.016.

41. Lee CC, Sheridan SC. A new approach to modeling temperature-related mortality. Non-linear autoregressive models with exogenous input. Environ Res. 2018;164:53-64. https://doi.org/10.1016/j.envres.2018.02.020

42. Casanova LM, Jeon S, Rutala WA, Weber DJ, Sobsey MD. Effects of Air Temperature and Relative Humidity on Coronavirus Survival on Surfaces. Appl Environ Microbiol. 2010;76(9):2712-7. https://doi.org/10.1128/AEM.02291-09.

43. Zhang Y, Li C, Feng R, Zhu Y, Wu K, Tan X, et al. The Short-Term Effect of Ambient Temperature on Mortality in Wuhan, China: A Time-Series Study Using a Distributed Lag Non-Linear Model. Int J Environ Res Public Health. 2016;13(7):722. https://doi.org/10.3390/ijerph13070722.

44. Guo Y, Barnett AG, Pan X, Yu W, Tong S. The Impact of Temperature on Mortality in Tianjin, China: A Case-Crossover Design with a Distributed Lag Nonlinear Model. Environ Health Perspect. 2011;119(12):1719-25. https://doi.org/10.1289/ehp.1103598.

45. Guo Y, Gasparrini A, Armstrong B, Li S, Tawatsupa B, Tobias A, et al. Global Variation in the Effects of Ambient Temperature on Mortality: A Systematic Evaluation. Epidemiology. 2014;25(6):781-9. https://doi.org/10.1097/EDE. 0000000000000165.

46. Luo Q, Li S, Guo Y, Han X, Jaakkola JJK. A systematic review and metaanalysis of the association between daily mean temperature and mortality in China. Environ Res. 2019;173:281-99. https://doi.org/10.1016/j.envres.2019. 03.044 .

47. Carder M, McNamee R, Beverland I, Elton R, Cohen GR, Boyd J, et al. The lagged effect of cold temperature and wind chill on cardiorespiratory mortality in Scotland. Occup Environ Med. 2005:62(10):702-10. https://doi.org/10.1136/oem.2004.016394.

48. Gasparrini A, Guo Y, Hashizume M, Lavigne E, Zanobetti A, Schwartz J, et al. Mortality risk attributable to high and low ambient temperature: a multicountry observational study. Lancet. 2015;386(9991):369-75. https://doi.org/10.1016/S0140-6736(14)62114-0.

49. Lin $H$, Zhang $Y, X u Y, X u X$, Liu T, Luo $Y$, et al. Temperature Changes between Neighboring Days and Mortality in Summer: A Distributed Lag Non-Linear Time Series Analysis. PLoS One. 2013;8(6):e66403. https://doi.org/10.1371/journal.pone.0066403.

\section{Publisher's Note}

Springer Nature remains neutral with regard to jurisdictional claims in published maps and institutional affiliations.
Ready to submit your research? Choose BMC and benefit from:

- fast, convenient online submission

- thorough peer review by experienced researchers in your field

- rapid publication on acceptance

- support for research data, including large and complex data types

- gold Open Access which fosters wider collaboration and increased citations

- maximum visibility for your research: over $100 \mathrm{M}$ website views per year

At $\mathrm{BMC}$, research is always in progress.

Learn more biomedcentral.com/submissions 